Article

\title{
Transferability of Process Parameters in Laser Powder Bed Fusion Processes for an Energy and Cost Efficient Manufacturing
}

\author{
Oliver Pannitz * and Jan T. Sehrt \\ Hybrid Additive Manufacturing, Ruhr University Bochum, 44801 Bochum, Germany; \\ Jan.Sehrt@ruhr-uni-bochum.de \\ * Correspondence: Oliver.Pannitz@ruhr-uni-bochum.de; Tel.: +49-234-32-23519
}

Received: 19 January 2020; Accepted: 17 February 2020; Published: 19 February 2020

check for updates

\begin{abstract}
In the past decade, the sales of metal additive manufacturing systems have increased intensely. In particular, PBF-LB/M systems (powder bed fusion of metals using a laser-based system) represent a technology of great industrial interest, in which metallic powders are molten and solidified layer upon layer by a focused laser beam. This leads to a simultaneous increase in demand for metallic powder materials. Due to adjusted process parameters of PBF-LB/M systems, the powder is usually procured by the system's manufacturer. The requirement and freedom to process different feedstocks in a reproducible quality and the economic and ecological factors involved are reasons to have a closer look at the differences between the quality of the provided metallic powders. Besides, different feedstock materials require different energy inputs, allowing a sustainable process control to be established. In this work, powder quality of stainless steel 1.4404 and the effects during the processing of metallic powders that are nominally the same were analyzed and the influence on the build process followed by the final part quality was investigated. Thus, a correlation between morphology, particle size distribution, absorptivity, flowability, and densification depending on process parameters was demonstrated. Optimized exposure parameters to ensure a more sustainable and energy and cost-efficient manufacturing process were determined.
\end{abstract}

Keywords: additive manufacturing; PBF-LB/M; powder characterization; sustainable process parameters; stainless steel $(1.4404 ; 316 \mathrm{~L})$; energy and cost-efficient manufacturing

\section{Introduction}

An additive manufacturing (AM) process is described as the incremental layer upon layer build-up of a three-dimensional workpiece and represents the third category next to subtractive and formative manufacturing [1]. This, in turn, leads to significant benefits, such as increased freedom of design, the realization of complex structures, and the integration of functions. One of the AM processes for direct manufacturing of metal parts is powder bed fusion of metals using a laser beam system (PBF-LB/M), in which metallic powders are molten and solidified in a layer upon layer manner by a focused laser beam [2]. The industry shows great interest in AM of metallic components, which is illustrated by rising sales figures for systems [3]. Stainless steel 1.4404 (EN: 14404 / X2CrNiMo17-12-2 / AISI 316L) is a stainless, austenitic steel and one of the most commonly produced steels using a PBF-LB/M system. The material is applied to a wide range of industrial areas, such as oil and gas, automotive, aerospace, and biomedical engineering, due to its high strength, ductility, corrosion resistance, and biocompatibility [4,5]. In particular, new design opportunities offer the possibility of manufacturing components with integrated functions and defined structure or even graded porosities to design weight-saving and stress-optimized components. The investigated material is particularly 
useful for medical devices, e.g., surgical devices with thin-walled structures and, alongside Ti and $\mathrm{Co}-\mathrm{Cr}$ alloys, for medical implants $[4,5]$. The ability to create complex lattice structures has resulted in a redesign of existing stainless steel components and lightweight structures in the automotive and aerospace industry to ensure more efficient and sustainable components [5].

However, in order to ensure sustainable production, the entire process chain must be taken into consideration. Starting with powder production, through transportation and processing of the powder in the PBF-LB/M system, up to the use of a durable component and recycling of the nonfused metal powder. Kellens et al. [6] emphasize that energy consumption during the PBF-LB/M process is dominated by laser exposure. This was confirmed by Liu et al. [7], who state that energy consumption depends on exposure parameters such as laser power, scanning speed, layer thickness, etc. on the process level. Thus, the correlation between powder characteristics, the PBF-LB/M-process itself, and the final part quality represent a significant area of focus for sustainable process management.

Great research efforts in the scientific community concerning stainless steel 1.4404 have addressed the correlation between input parameters (e.g., particle size distribution, chemical composition, process parameters, etc.) and output parameters (e.g., mechanical properties, relative density, microstructure, etc.). Process parameters consist of a large number of variables, including laser power, scanning speed, layer thickness, and hatch distance, but also material-based input parameters, such as sphericity, particle size distribution, flowability, and absorptivity are essential [8,9]. Yang et al. [10] investigated the absorption behavior of AlSi12 powder and its correlation to different particle sizes. As a result, the dependence of both parameters was visible. With an increasing particle size, the absorption of laser beam decreases. A similar result was reported by Gu et al. [11], who compared the absorption behavior of SiC and TiB2-reinforced AlSi10Mg. The reinforced material exhibited an increased absorption behavior compared to the original feedstock material, due to multiple scattering of the laser beam. Furthermore, the powder's flowability is crucial for the generation of homogenous distribution of a powder layer. According to Spierings et al. [12], an overview of different devices for determining the flowability characteristics of metallic powder materials is given. According to his research, to quantify the interparticle friction, the Schulze ring shear tester and Hausner ratio (ratio of tapped and bulk density) do not represent the real powder distribution in PBF-LB/M systems. Nevertheless, these measurements are still mentioned in the VDI 3405 Part 2.3 Guideline [13]. In addition, the morphology of metallic powder particles has an influence on the flowability. A more spherical powder exhibits better flowability characteristics and powder bed densities [14,15].

Furthermore, efforts have been made to investigate a process window for 1.4404 to ensure reproducible part quality. For instance, Cherry et al. [16] and Di Wang et al. [17] investigated the effect of process parameters on mechanical properties of 1.4404 parts. According to their results, the part density showed a strong dependence on the laser volume energy density. In addition, the as-built material microhardness increased simultaneously to a decreasing porosity to a maximum of $225 \mathrm{HV}$ at a density of $99.62 \%$. Other researchers presented an approach to find the optimum laser process parameters resulting in dense parts, homogeneous melt pools, and predictable microstructure [18-23]. Casati et al. [24] and Kruth at al. [25] investigated the as-built microstructure of stainless steel samples. The periodic melt pools and selected scanning strategy were clearly visible and elongated grains made up of cellular substructures were the result of epitaxial solidification. Furthermore, the complete consideration of the entire process chain is important. Chen et al. [26] presented the influence of different powder feedstocks regarding particle size distribution on mechanical properties and densification. In their results, a fine $(\sim 16 \mu \mathrm{m})$ and spherical powder obtained the highest mechanical properties and densification due to a high packing density and, in this case, decreased oxygen content. It is important to adjust process parameters to the used feedstock [27].

In summary, a comprehensive characterization of material 1.4404 is shown. Since this material is frequently used in the industrial and research environment, the freedom to choose a suitable supplier of the metal powder and the associated advantages concerning costs and energy efficiency are very attractive. System manufacturers provide specific standard parameters to achieve the best 
possible results in terms of component quality. Thus, the main criterion for the transferability of process parameters is the component quality with regard to the relative density, hardness testing, microstructural analysis, and melt pool characteristics. Consequently, independent use of a PBF-LB/M system is given.

In this work, feedstocks of five metallic powders of stainless steel 1.4404 were characterized by analyzing the particle size distribution, morphology, flowability, and absorption behavior. A standardized build job exhibiting different process parameters provided information concerning the variation of the powder's actual processability and transferability of the system's standard parameters, followed by the analysis of microstructure, relative density, and hardness. Based on the results, an approach to quantify the correlation between powder and part quality was developed. Furthermore, the economic evaluation of the feedstock represents an important factor for the industrial and research environment. Finally, the investigated parameters enable the opportunity to optimize the PBF-LB/M process by choosing more sustainable parameter sets.

\section{Materials and Methods}

\subsection{Processing}

The metallic samples were manufactured using the PBF-LB/M system TruPrint 1000 of Trumpf (Germany). The TruPrint 1000 is equipped with an Nd:YAG fiber laser (wavelength of $\lambda=1064 \mathrm{~nm}$ ) with a maximum laser power of $200 \mathrm{~W}$ and a focal diameter of $30 \mu \mathrm{m}$. An F-theta lens ensures that the focal point of the laser beam is positioned in the working plane. The system enables a maximum build size of $100 \mathrm{~mm}$ (diameter) and a height of $100 \mathrm{~mm}$. Furthermore, the components and the powder inside of the build chamber are protected against oxidation by a nitrogen atmosphere. Figure 1 illustrates the schematic diagram for PBF-LB/M processes. The recoating mechanism consists of a rubber $x$-profile and distributes a thin layer of metal powder from the feed region over the build platform. Afterwards, the applied layer is selectively molten according to the cross-sections of the parts and metallurgically bonded to the underlying layer. As soon as this step is completed, the build platform is lowered and a new layer of powder is applied. These steps are repeated until the parts are finished.

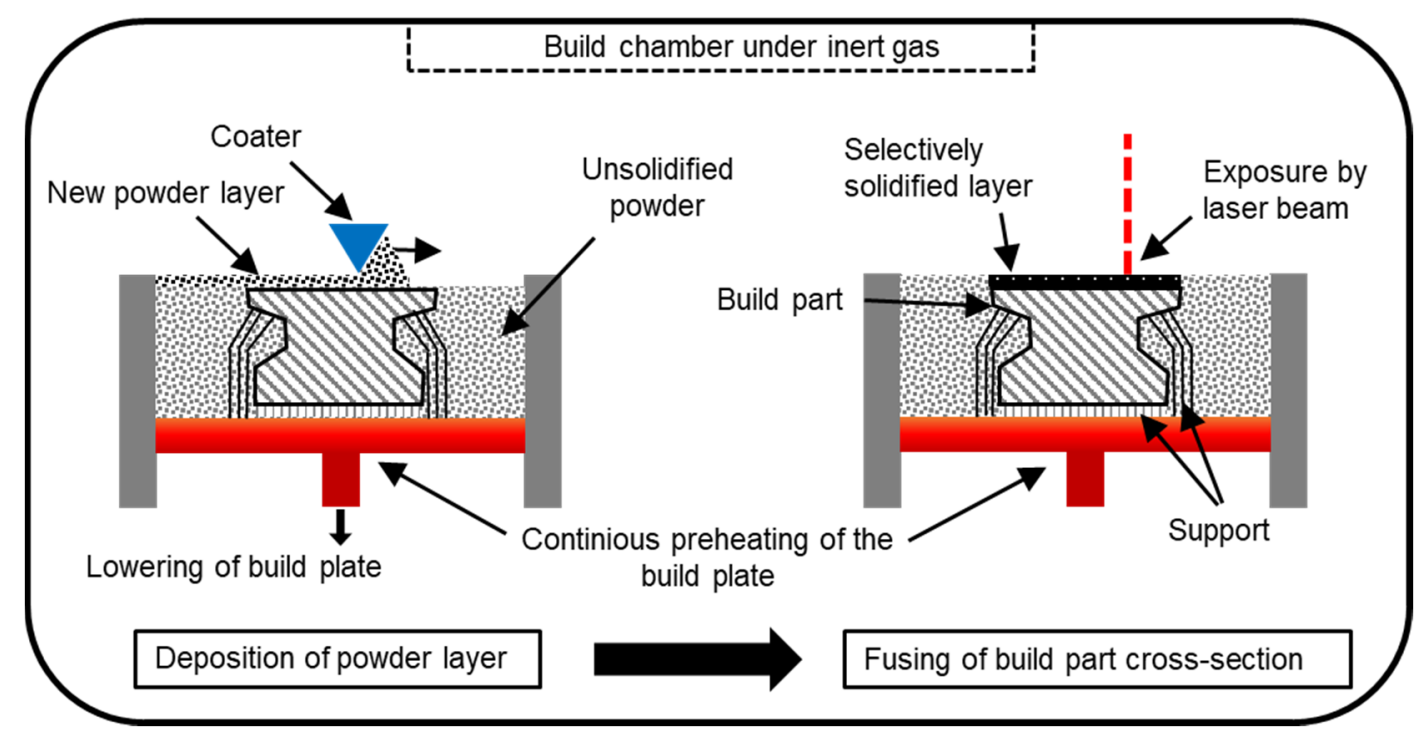

Figure 1. Schematic of powder bed fusion of metals using a laser-based system (PBF-LB/M) process.

\subsection{Powder Material}

The particle size distribution (PSD) and morphology of stainless steel 1.4404 provided by five different suppliers were investigated. The PSD was determined by the Mastersizer 2000 of Malvern Panalytical Ltd. (UK, Netherlands), which operates on the laser diffraction principle and can detect 
particles in a range of $0.02 \mu \mathrm{m}$ to $2000 \mu \mathrm{m}$. According to VDI 3405, Part 2.3 [13], laser diffraction analysis is recommended to obtain the PSD. A method of obtaining a single number to describe an irregularly shaped particle is to compare some features of the actual particle with an imaginary sphere. In this case, the Mastersizer 2000 uses the volume as a size parameter of the particle to measure its size. As the different stainless steel powders were analyzed by the same method, a transferability of the results is guaranteed. The powder morphology was analyzed by the scanning electron microscope (SEM) Gemini2 Merlin by Carl Zeiss AG (Germany). The different powders were steamed with $15 \mathrm{~nm}$ of gold to increase electrical conductivity. According to Cooke et al. [28], the sphericity of powder particles is defined by Equation (1), where a value of 1 indicates a perfect circle. As the value approaches 0 , it indicates an elongated shape. The analysis was carried out by using the particle analyzer of the open-source software ImageJ.

$$
\text { Sphericity }=\frac{4 \pi \times \text { area of the particle outline }}{\text { perimeter of the particle outline } e^{2}}
$$

According to DIN EN 10088-1 [29], the chemical composition of 1.4404 is presented in Table 1. The suppliers A, B, C, and E provided gas-atomized powders, whereas supplier D provided vacuum gas-atomized powder.

Table 1. Nominal chemical composition of 1.4404 stainless steel powder [29].

\begin{tabular}{cccccccccc}
\hline Element & $\mathbf{F e}$ & $\mathbf{C r}$ & $\mathbf{N i}$ & $\mathbf{S i}$ & $\mathbf{M o}$ & $\mathbf{M n}$ & $\mathbf{P}$ & $\mathbf{S}$ & $\mathbf{C}$ \\
\hline $\begin{array}{l}\text { Content } \\
\text { in wt.\% }\end{array}$ & bal. & $16.5-18.5$ & $10.0-13.0$ & $\max .1 .0$ & $2.0-2.5$ & $\max .2 .0$ & max. & max. & max. \\
\hline
\end{tabular}

For an economic comparison, the various relative prices for stainless steel 1.4404 of the five suppliers are shown in Table 2, with supplier B as reference. The listed prices are based on a maximum purchase quantity of $100 \mathrm{~kg}$. The properties of the stainless steel 1.4404 powder recommended by the system manufacturer are characterized by an increased sphericity and a decreased particle size. Among the powder materials used in this work, this powder is also represented.

Additionally, the absorptivity of the samples was analyzed by the Nicolet iS20 FTIR spectrometer from Thermo Fisher Scientific. The DiffusIR from Pike was used as an accessory for the measurement. The measurements were carried out at room temperature. An aluminum mirror served as a reference for the background measurement. All spectra were recorded using a white light source, an XT-KBr beam splitter, and an MCT/A detector range of 4000 to $11000 \mathrm{~cm}^{-1}$ with 256 scans and a spectral resolution of $4 \mathrm{~cm}^{-1}$. Three spectra from each of the four samples were recorded to check the reproducibility of the measurement. The wavenumber of $9400 \mathrm{~cm}^{-1}$ (reciprocal value of wavelength) corresponds to a wavelength of $\lambda=1064 \mathrm{~nm}$ (wavelength of Nd:YAG laser utilized in a PBF-LB/M system). A Hall flowmeter was used to determine the bulk density according to DIN EN ISO 3923-1 [30] of each powder material, and subsequently, the Hausner ratio as an indicator for flowability characteristics was determined. Furthermore, the flow rate was analyzed according to DIN EN ISO 4490:2018 [31]. In total, three measurements were carried out for each sample.

Table 2. Pricing of stainless steel powder 1.4404 in dependence on different suppliers.

\begin{tabular}{cccccc}
\hline Supplier & A & B & C & D & E \\
\hline Pricing & 2.42 & 1 & 1.03 & 1.77 & 1.32 \\
\hline
\end{tabular}

\subsection{Mechanical and Microstructural Properties}

The Keyence VHX 6000 digital microscope of Keyence Corporation (Japan) was used to analyze the microstructure and relative density of the samples. The entire cross-section of the infill section of a 
sample is recorded to evaluate and compare the relative density. The accumulated area of all pores can be recorded with the aid of particle/contamination analysis. The calculation of the relative density $\rho_{r e l}$ follows Equation (2):

$$
\rho_{\text {rel }}=\frac{A_{\text {pore }}}{A_{\text {extr }}} \times 100 \%
$$

where $A_{\text {pore }}$ represents the total area of all recorded pores and $A_{\text {extr }}$ is the extraction area of the whole sample. The $\mathrm{HV}_{10}$ hardness tests were carried out on five samples for each material, manufactured with standard parameters using the Vickers hardness testing machine KB 30 S from KB Prüftechnik GmbH (Germany).

\subsection{Process Parameters for Test Samples}

In order to evaluate the processability and transferability of the system's standard process parameters, it is important to set a laser parameter window. The positioning and alignment of the samples, as well as the configuration of exposure parameters, was carried out via the preprocessing software Materialise Magics by Materialise NV (Belgium). Thus, a varying volume energy density $E_{V}$ was ensured. This was calculated from the laser power $P_{L}$, scanning speed $v_{s}$, hatch distance $h_{d}$, and layer thickness $D_{s}$, as shown in Equation (3) [32].

$$
E_{V}=\frac{P_{L}}{v_{s} \times h_{d} \times D_{S}}
$$

The specimens had a size of $5 \times 5 \times 5 \mathrm{~mm}^{3}$ and were connected to the build platform by an inverted pyramid shape with a height of $3 \mathrm{~mm}$. This allowed an easy removal of the samples from the build platform (cf. Figure 2). For each stainless steel powder, a total of 25 samples with varying volume energy densities were produced. As illustrated in Figure 2a, the scanning speed varied between $560 \mathrm{~mm} / \mathrm{s}$ and $840 \mathrm{~mm} / \mathrm{s}$ and the nominal laser power varied between $96 \mathrm{~W}$ and $144 \mathrm{~W}$. Sample \#13 represented the standard parameters of the TruPrint 1000 for this specific feedstock. In Figure 2b, a 3D model of the manufactured samples and the applied alternating $\left(90^{\circ}\right)$ checkerboard scan strategy is presented. The layer thickness was kept constant at $20 \mu \mathrm{m}$ and the hatch distance at $90 \mu \mathrm{m}$.

(a)

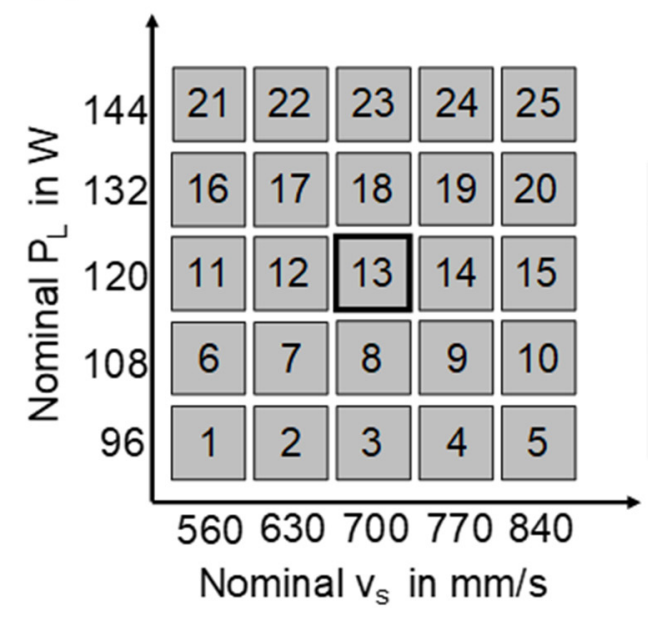

(b)

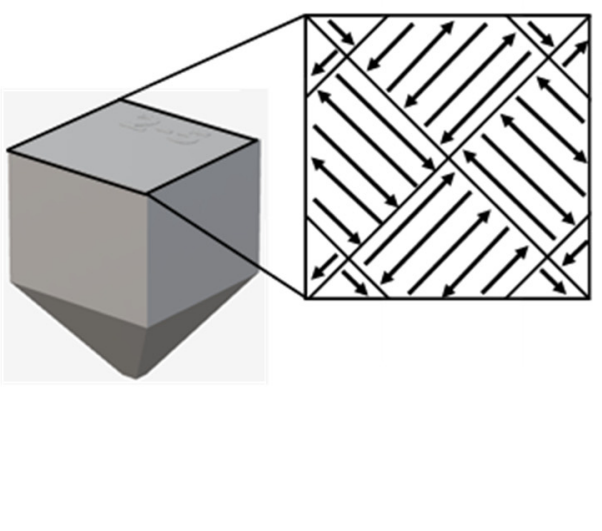

Figure 2. (a) Experimental setup with 25 samples with a varying nominal laser power $P_{L}$ and a varying scanning speed $\mathrm{v}_{\mathrm{s}}$. Sample \#13 represents the standard parameters of the used PBF-LB/M system. (b) 3D model of a sample with an illustration of the checkerboard scan strategy. 


\section{Results}

\subsection{Particle Size Distribution and Particle Morphology}

All powders were characterized by a Gaussian-like particle size distribution. Differences concerning the $\mathrm{d}_{10}, \mathrm{~d}_{50}$, and $\mathrm{d}_{90}$ values were noticeable as depicted in Figure 3. Suppliers A, D, and E exhibit a decreased particle size distribution $\left(\mathrm{d}_{50}\right)$ of approx. $10 \mu \mathrm{m}$ in contrast to the powder provided by suppliers B and C. Furthermore, a multimodal particle size distribution was visible with an increased volume at $8-10 \mu \mathrm{m}$ and $10-15 \mu \mathrm{m}$ at powders $C$ and $D$, respectively.

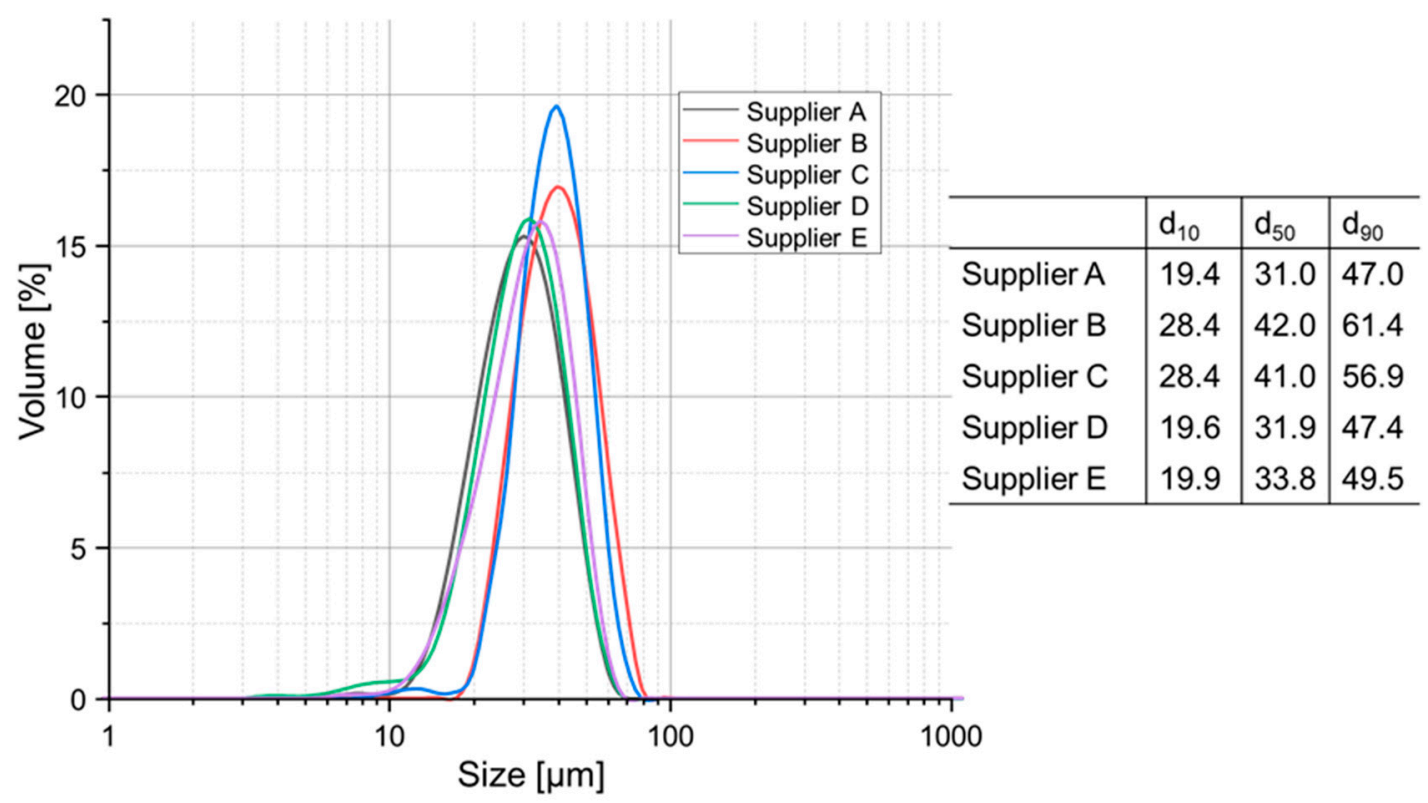

Figure 3. Particle size distribution of five different stainless steel 1.4404 powders including $\mathrm{d}_{10}, \mathrm{~d}_{50}$, and $d_{90}$ values.

The SEM images (cf. Figure 4) confirm the increased amount of smaller particles. In total, the predominant amount of particles exhibited an almost spherical shape. The powder of supplier A was characterized by an increased amount of spherically shaped particles in contrast to the powder of supplier C. Here, the surface of most particles was not smooth due to particles covered by a large number of small satellites and also partially agglomerated particles. Furthermore, particle clusters and irregularly shaped particles were visible. Most of the particles of powder B were spherically shaped. Nevertheless, a small amount of satellites were recorded. The powder of supplier D was characterized by an increased amount of small particles that formed irregular clusters. Particles with a diameter of about $50 \mu \mathrm{m}$ contain had increased presence of satellites. The predominant amount of particles provided by supplier E showed a spherical shape and contained smaller particles with a diameter of approximately 10-20 $\mu \mathrm{m}$. Furthermore, the surface of the particles was smooth. The SEM images correspond to the calculation of the sphericity (cf. Table 3). The increased sphericity of powder B with a value of 0.94 and the decreased values of powder C and D, 0.87 and 0.89 , respectively, were noticeable. The best sphericity of 0.94 at powder B also resulted in the best flowrate (cf. Figure 5b). 

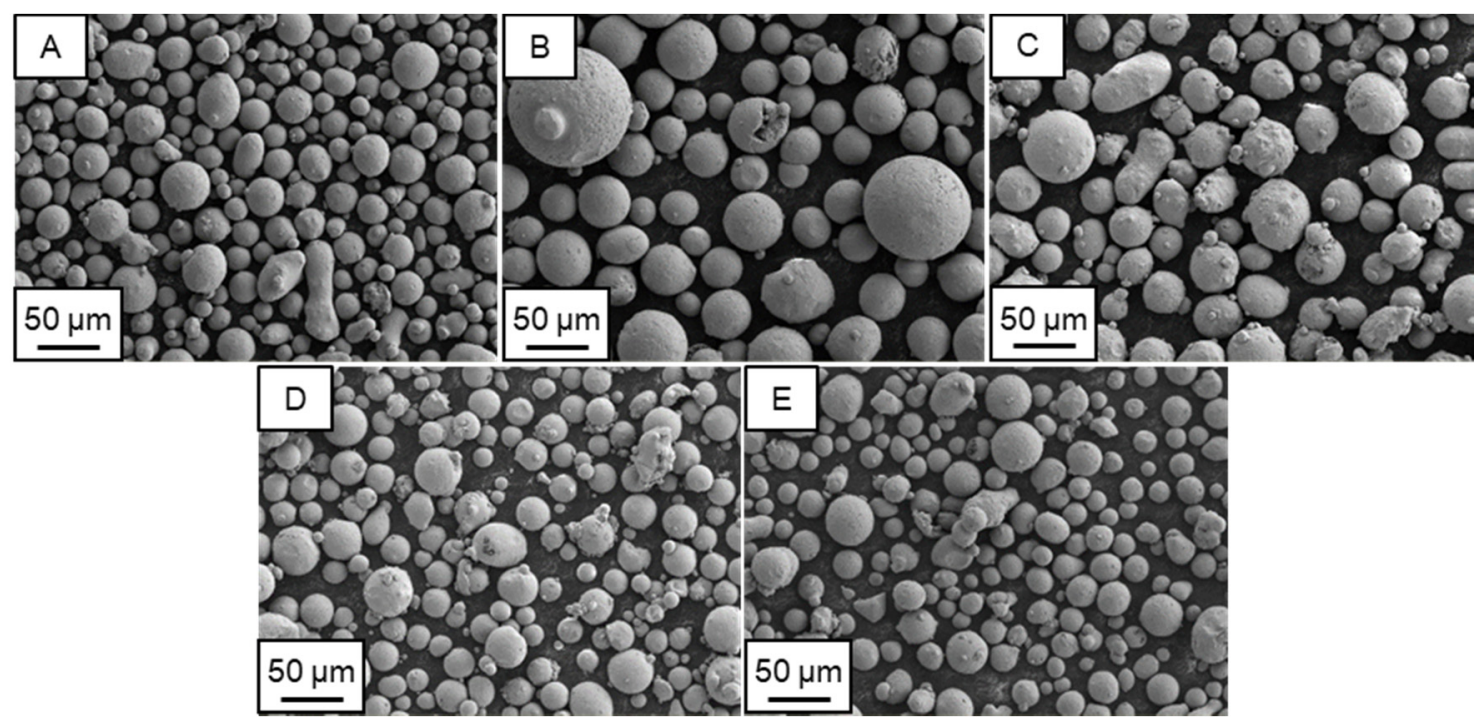

Figure 4. Morphology of five different stainless steel 1.4404 powders.

Table 3. The sphericity of five different stainless steel 1.4404 powders in dependence on different suppliers.

\begin{tabular}{cccccc}
\hline Supplier & A & B & C & D & E \\
\hline Sphericity & 0.91 & 0.94 & 0.87 & 0.89 & 0.92 \\
\hline
\end{tabular}

\subsection{Flowability}

The duration it takes for $50 \mathrm{~g}$ of stainless steel powder to flow through a standardized funnel, is presented in Figure 5, with the Hausner ratio on one hand and flow rate on the other. Powder A exhibited the lowest value, with a Hausner ratio of approximately 1.08 , while powder $\mathrm{C}$ showed the highest value of approximately 1.19. This led to a difference of about $9 \%$. In addition, powders $C$ and D showed the largest standard deviation. Powder B was comparable to powder A. Considering the flow rate, the missing values of powder $C$ and $D$ are noticeable. The powders could not be converted into a flowing state. Powder B showed the most consistent and decreased flow rate compared to power $\mathrm{A}$ and $\mathrm{E}$.

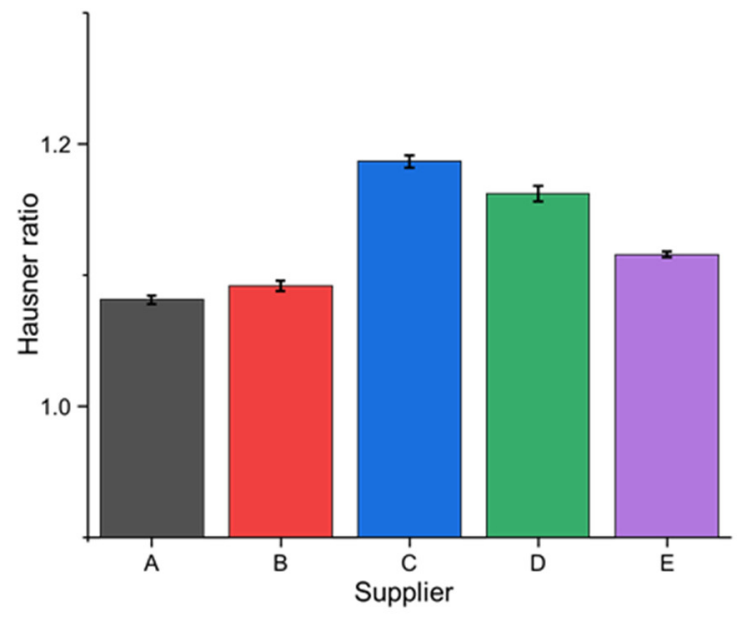

(a)

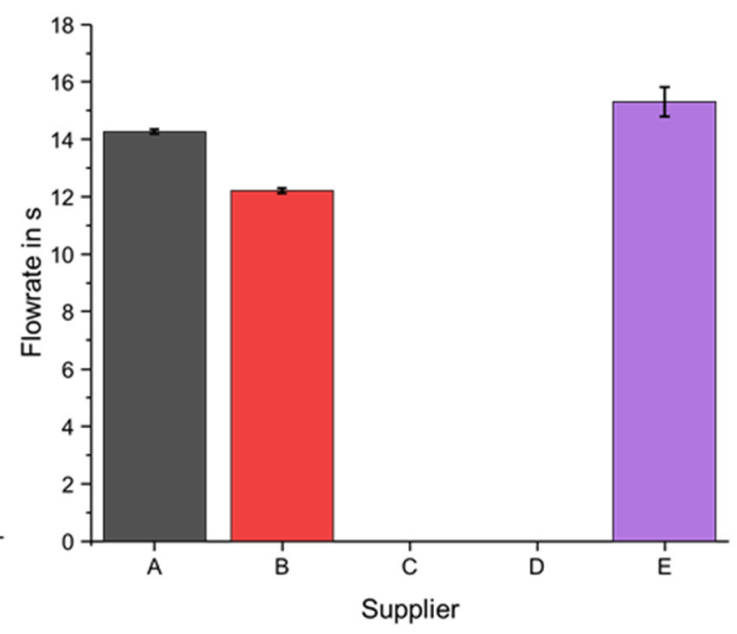

(b)

Figure 5. (a) Hausner ratio and (b) Flowrate of five different stainless steel 1.4404 powders. 


\subsection{Absorptivity}

The results of the absorption measurement are presented in Figure 6. The reflection is plotted on the y-axis whereas the wavenumber is plotted on the x-axis. The plotted wavenumber of $9400 \mathrm{~cm}^{-1}$ approximately corresponds to a wavelength of $\lambda=1064 \mathrm{~nm}$. The powder from supplier A exhibited the highest reflection of $11.61 \%$ and thus the lowest absorption. The powder provided by supplier $\mathrm{D}$ showed the highest absorption with a reflection of $9.28 \%$. This led to a difference of approximately $20 \%$. Powder B and C had almost identical values of approximately $10 \%$, although the previous curve was slightly different. Powder E is located in the middle between powders B, C, and A.

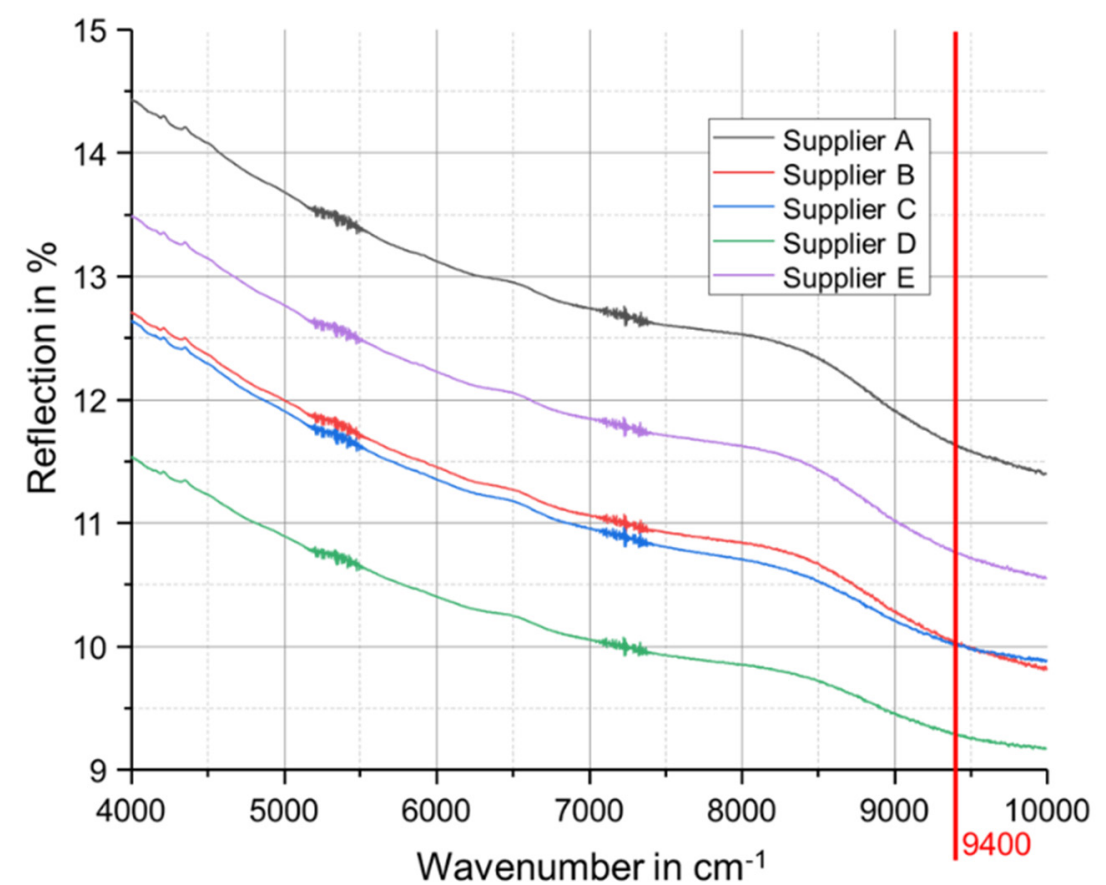

Figure 6. Absorption measurement of five different stainless steel 1.4404 powder feedstocks provided by different suppliers; Reflection was measured with respect to the wavenumber; wavenumber of $9400 \mathrm{~cm}^{-1}$ corresponds to a wavelength of $\lambda=1064 \mathrm{~nm}$.

\subsection{Relative Density}

Figure 7 shows the tendency of the relative density according to the experimental setup. The section lined in red represents a process window that allows sample generation with a relative density $\rho_{\text {rel }} \geq$ $99.5 \%$. An increased value of the relative density can simultaneously be registered to the increased volume energy density. The highest density is shown for all suppliers with the highest volume energy density $\left(E_{V}=142.85 \mathrm{~J} / \mathrm{mm}^{3}\right)$. The diagonally arranged samples (sample \#1, \#7, \#13, \#19, and \#25) were produced with the same volume energy density $\left(E_{V}=95.23 \mathrm{~J} / \mathrm{mm}^{3}\right)$. Overall, samples of supplier $\mathrm{C}$ had the lowest density with an average value of $\rho_{\text {rel }}=99.11 \%$ and showed an inconsistent behavior compared to other sample groups. Samples of supplier A showed the highest average value of $\rho_{\text {rel }}=$ $99.77 \%$. Furthermore, it was evident that powders provided by suppliers A, B, and D exceeded the border of $\rho_{\text {rel }}=99.5 \%$ with a volume energy density of $E_{V}<80 \mathrm{~J} / \mathrm{mm}^{3}$. By increasing the scanning speed of the laser by $10 \%$ compared to standard parameters, the same density values could be achieved with powder A and B. Powder D exhibited a constant relative density with a $10 \%$ decrease in laser power. 


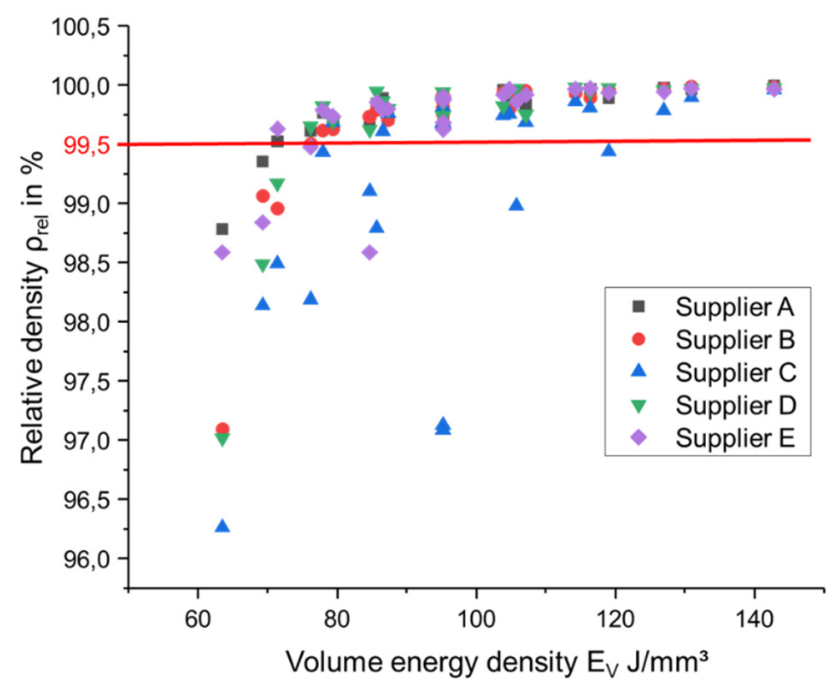

Figure 7. Relative density of stainless steel 1.4404 specimens manufactured by PBF-LB/M with varying volume energy densities.

\subsection{Microstructure and Hardness Testing}

The periodic melt pool geometry of the manufactured samples becomes noticeable after etching and shows that particles have fused within the molten and solidified zones (cf. Figure 8) [16]. The layer upon layer manner and the overlap of adjacent laser scan tracks of sample \#13 are presented. The designation of the samples corresponds to the designation of the suppliers. The structure occurs due to the partial remelting of the laser scan tracks [24]. The average melt pool width of sample \#13 manufactured with powder D and B was approximately $150 \mu \mathrm{m}$ and $148 \mu \mathrm{m}$, respectively, which represent the highest widths. Sample \#13 manufactured with powder $C$ was characterized by the lowest average value of $128 \mu \mathrm{m}$. Despite a focal diameter of $30 \mu \mathrm{m}$, increased melt pool widths were observed at the investigated levels of powder materials. This could be related to an increased power density. According to Hitzler et al. [33] and Casati et al. [24], subsequent heat inputs by the generation of the adjacent scan track or the subsequent layer changes the grains of the already solidified material, which is also called epitaxial growth and describes the tendency of needle-like grain growth along the direction of the maximum temperature gradient. The large number of inclusions in sample $\mathrm{D}$ and the irregular arrangement of the melt pools are conspicuous. The effects are particularly represented at the boundaries of the melt pools (white arrows in Figure 8). In addition, some microcracks are visible.

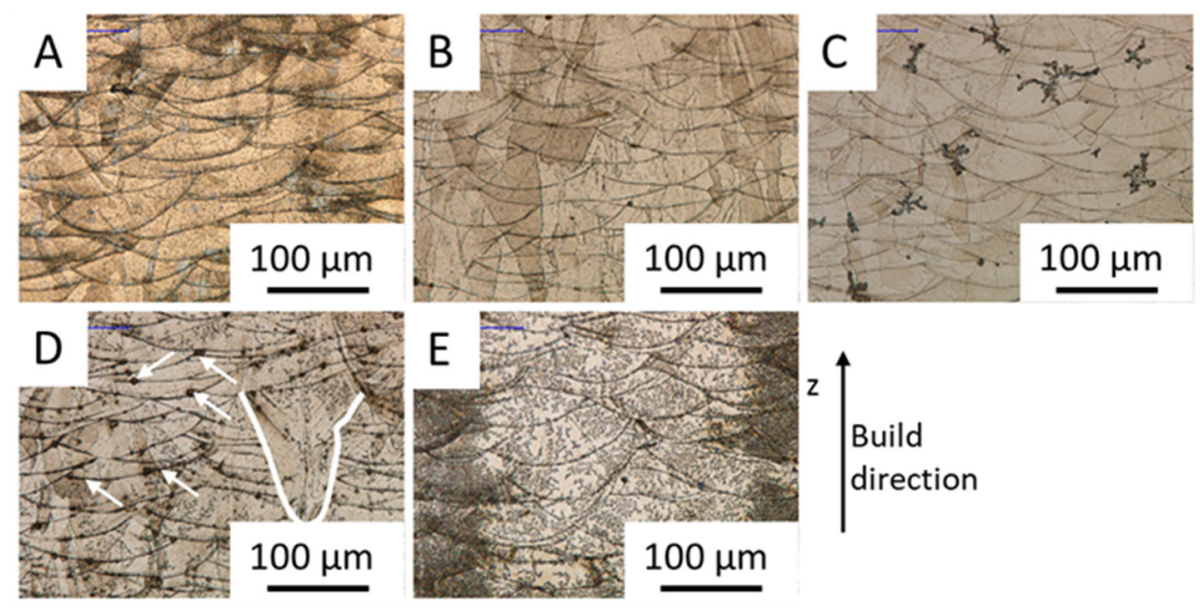

Figure 8. Microstructure of five 1.4404 stainless steel samples manufactured by PBF-LB/M with the system's standard parameters (sample \#13). 
A hardness test was performed on the samples produced with standard process parameters (sample \#13) of the PBF-LB/M system. The hardness test results showed comparable values for samples from suppliers A, B, C, and E (cf. Figure 9). Only sample D had a significantly lower value. The mean value of five measurements was $195.4 \mathrm{HV}_{10}$ and is therefore approximately $19 \%$ lower than the highest mean value of sample $\mathrm{E}$.

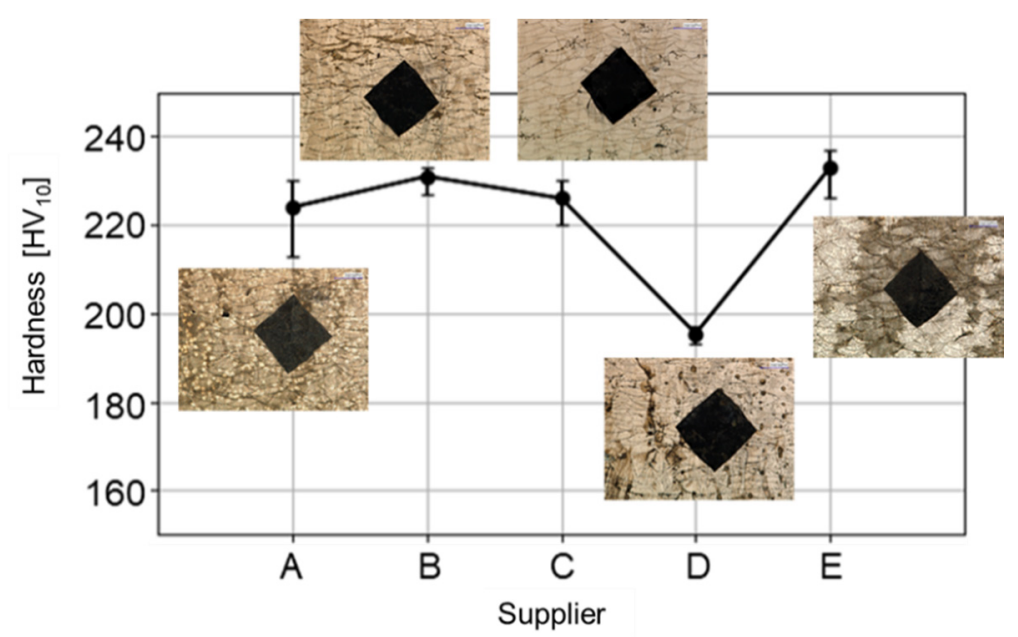

Figure 9. Hardness testing $\left(\mathrm{HV}_{10}\right)$ of five 1.4404 stainless steel samples manufactured by PBF-LB/M with the system's standard parameters (sample \#13).

\section{Discussion}

The particle size distribution and morphology showed a significant influence on flowability, absorption behavior, and the final component quality. It is evident that powder A and B showed the best flowability according to the Hausner ratio and flow rate. Both powders were characterized by increased sphericity, although exhibited different particle size distributions. Zou et al. [14] have already reported a correlation between morphology and the Hausner ratio. Thus, the Hausner ratio decreases simultaneously to increasing sphericity. In this case, however, the magnitude of the present metal powder was not assumed. According to Schulze [34], in this type of dry and fine-grained bulk material, interparticulate cohesive forces, such as Van der Waal's forces, are involved, which are based on electrical dipole moments of atoms and molecules. A further influencing factor is humidity. This allows a formation of liquid bridges between particles, which consequently result in agglomeration and thus impair the flowability of the metal powder. Consequently, a potential reason for the decreased flowability of powder $\mathrm{C}$ and $\mathrm{D}$ is the increased fine fraction (multimodal particle size distribution with an increased amount of small particles), which leads to the cohesive forces mentioned above. Comparable results were also reported by Brika et al. [15]. Due to the failure of the flow rate (powder $\mathrm{C}$ and $\mathrm{D}$ ), it appears that this powder is not suitable for the PBF-LB/M process and the distribution of a thin layer of powder. Thus, the transferability of the measuring methods is questionable, since during the PBF-LB/M process, a translational movement, is performed by the recoater. Other measuring instruments, such as a powder rheometer or a self-invented powder distribution test rig with an in situ observation of a powder layer, are considerable, which allow the recording of measured values closer to the PBF-LB/M process.

According to Gu et al. [11] and Yang et al. [10], smaller particle size distributions are beneficial for an increased absorptivity due to the multiple scattering of the laser beam inside of the powder bed. The increased fine fraction of powder $\mathrm{D}$ could be the predominant factor for increased absorptivity. The large specific surface area of smaller particle sizes, and consequently the multiple scattering, is beneficial for an increased absorption of laser radiation. In addition, powders B and C exhibited the same tendency in particle size distribution and absorptivity. Nevertheless, powder D and E indicate further influencing factors. One influencing factor might be the surface roughness of the particles. 
The increased amount of satellites in powders $C$ and $D$ could also lead to multiple scattering of the laser beam, and consequently to an increased amount of beam dumps.

Furthermore, the results of the relative density confirmed that the use of powders with a decreased particle size distribution could achieve better and more consistent densification of the PBF-LB/M specimens than larger particle size distributions due to the complete melting of the powder material [26,27]. The powder materials from supplier B and C exhibited comparable particle size distributions. Nevertheless, there was a difference in densification. A correlation to the morphology and the resultant flowability can be assumed. The inferior values regarding the flowability of powder $\mathrm{C}$ led to a partially more inhomogeneous distribution in the powder bed, which could be beneficial for the formation of pores. Since the sample prepared with standard parameters achieved a consistently high relative density ( $\rho_{\text {rel }} \geq 99.5 \%$ ), these process parameters can be transferred to other powder materials of the same class. However, in order to achieve higher qualities and more sustainable process management, small adjustments for each feedstock are necessary.

Concerning the hardness testing, sample \#13 manufactured with powder D was characterized by a decreased hardness $\mathrm{HV}_{10}$. The relative density only differed minimally among the manufacturers. Thus, no conclusions can be drawn about the respective correlation between density and hardness testing. However, according to Cherry et al. [16], porosity is a decisive factor in the hardness of a component. As porosity increases, hardness decreases. An influence of the microstructure characteristics is a possible cause for the significant difference in hardness testing. Small inclusions and microcracks could lead to decreased hardness values.

In order to establish an energy-efficient parameter window, the volume energy density can be reduced. The results of densification indicate that a relative density of $\rho_{\text {rel }}=99.5 \%$ can be achieved with lower energy input. Thus, as in this case, the laser power can be reduced or the scanning speed increased. If the component to be manufactured is not heavily loaded, a relative density of $\rho_{\text {rel }}=$ $99.0 \%$ (as recommended by VDI 3405) is sufficient. In addition, further control variables, such as hatch distance, layer thickness, and powder application speed, must be taken into consideration. The latter can correlate with the flowability of the powder, and thus, result in increased production speed. Concerning the powder, a good combination of flowability and absorptivity is required to ensure reproducible and sustainable process management.

In the industrial and research environment, tons of metal powders are usually ordered in the long run, so a previous evaluation of different metal powders of the same material classes makes sense. On the market, there are strong price differences between the suppliers. The lowest price (supplier B) was only approximately $40 \%$ of the cost of the most expensive supplier (supplier A). However, most likely the application purpose has priority. If heavy-duty components are required, the mechanical properties must be tested and guaranteed. To save costs, third-party powders can be used. The tests listed in this paper show mostly comparable mechanical properties, microstructures, and densities so that mainly a transferability of standard process parameters is given.

\section{Conclusions}

The feedstock of five powders of stainless steel 1.4404 provided by five different suppliers were characterized by analyzing the particle size distribution, morphology, flowability, and absorptivity. A standardized build job exhibiting different process parameters provided information concerning the variation of the powder's actual processability and transferability of the system's standard parameters, followed by the analysis of relative density, microstructure, and hardness. In the end, a statement about sustainable parameter sets was made. On the one hand, spherical powder particles and a Gaussian-like particle size distribution with a decreased fine fraction are beneficial for an increased flowability. On the other hand, an increased fine fraction and an increased surface roughness of the particles leads to multiple scattering of laser radiation, and consequently, to an increased absorptivity. The predominant factor in this work regarding the processability of stainless steel 1.4404 was the flowability of the powder. The powders provided by suppliers A, B. and E exhibited good flowability values and 
were characterized by a reproducible component quality at different energy inputs. In addition, the adjustment of exposure parameters is the decision of the system operator and a change of the existing powder quality is not directly possible. Furthermore, the investigations showed a transferability of standard parameters of the PBF-LB/M system regarding the measured quantities. In spite of different particle size distributions and morphological properties, the output parameters showed almost identical values, with simultaneously large cost differences. However, depending on needs and applications, the parameters should still be slightly adjusted in order to achieve the highest quantities as well as a more energy-efficient parameter window. As a starting point for the adaption of the parameters, the default parameters of the favored material class can be used.

Therefore, it is advisable to process a test batch of powder to test for the required quality requirements of the components before large quantities of powder are purchased from the supplier. In the future, flowability testing using a powder rheometer and an in situ observation of the powder distribution must be considered in order to establish a better correlation between the test methods and actual processability, and consequently, to identify a faster and more homogeneous generation of a powder bed. The consideration of output parameters includes an extended analysis of the hardness, as well as the determination of surface characteristics and fatigue and tensile strength. This, in turn, leads to a detailed characterization of the powder and component properties. Finally, in order to evaluate how much energy is saved to the full energy consumption per $\mathrm{kg}$, the absolute energy consumption using standard and optimized exposure parameters for a standardized build job must first be determined. This is a highly interesting idea for future scientific research.

Author Contributions: Data curation, O.P.; funding acquisition, J.T.S.; investigation, O.P.; methodology, O.P.; supervision, J.T.S.; writing-original draft, O.P.; writing-review and editing, J.T.S. All authors have read and agreed to the published version of the manuscript.

Funding: This research was funded by the Deutsche Forschungsgemeinschaft (DFG, German Research Foundation)—410107213, priority program "Materials for Additive Manufacturing", SPP 2122. The authors gratefully acknowledge the financial supports.

Acknowledgments: This research has been supported by the Deutsche Forschungsgemeinschaft (DFG, German Research Foundation), priority program "Materials for Additive Manufacturing", SPP 2122. The authors gratefully acknowledge the financial supports.

Conflicts of Interest: The authors declare no conflict of interest.

\section{References}

1. Gebhardt, A. Additive Fertigungsverfahren. In Additive Manufacturing Und 3D-Drucken Für Prototyping-Tooling-Produktion, 5th ed.; Hanser: München, Germany, 2016.

2. Deutsches Institut für Normung e. V. Additive Manufacturing-General Principles-Terminology; Beuth Verlag GmbH: Berlin, Germany, 2018.

3. Wohlers, T.T. 3D Printing and Additive Manufacturing State of the Industry; Wohlers Report; WOHLERS Associates: Fort Collins, CO, USA, 2018.

4. Herzog, D.; Seyda, V.; Wycisk, E.; Emmelmann, C. Additive manufacturing of metals. Acta Mater. 2016, 117, 371-392. [CrossRef]

5. Yap, C.Y.; Chua, C.K.; Dong, Z.L.; Liu, Z.H.; Zhang, D.Q.; Loh, L.E.; Sing, S.L. Review of selective laser melting: Materials and applications. Appl. Phys. Rev. 2015, 2, 41101. [CrossRef]

6. Kellens, K.; Yasa, E.; Renaldi, W.; Dewulf, W.; Kruth, J.P.; Duflou, J.R. Energy and Resource Efficiency of SLS/SLM Processes. In Proceedings of the 23rd Solid Freeform Fabrication Symposium, Austin, TX, USA, 6-8 August 2012; pp. 1-16.

7. Liu, Z.Y.; Li, C.; Fang, X.Y.; Guo, Y.B. Energy Consumption in Additive Manufacturing of Metal Parts. Procedia Manuf. 2018, 26, 834-845. [CrossRef]

8. Zhang, B.; Dembinski, L.; Coddet, C. The study of the laser parameters and environment variables effect on mechanical properties of high compact parts elaborated by selective laser melting 316L powder. Mater. Sci. Eng. A 2013, 584, 21-31. [CrossRef] 
9. Sehrt, J.T. Möglichkeiten Und Grenzen Bei Der Generativen Herstellung Metallischer Bauteile Durch Das Strahlschmelzverfahren; Duisburg-Essen University: Duisburg, Germany, 2010.

10. Yang, Y.; Gu, D.; Dai, D.; Ma, C. Laser energy absorption behavior of powder particles using ray tracing method during selective laser melting additive manufacturing of aluminum alloy. Mater. Des. 2018, 143, 12-19. [CrossRef]

11. Gu, D.; Yang, Y.; Xi, L.; Yang, J.; Xia, M. Laser absorption behavior of randomly packed powder-bed during selective laser melting of SiC and TiB2 reinforced Al matrix composites. Opt. Laser Technol. 2019, 119, 105600. [CrossRef]

12. Spierings, A.B.; Voegtlin, M.; Bauer, T.; Wegener, K. Powder flowability characterisation methodology for powder-bed-based metal additive manufacturing. Prog. Addit. Manuf. 2016, 1, 9-20. [CrossRef]

13. Verein Deutscher Ingenieure e. V. VDI 3405 Blatt 2.3. Additive Fertigungsverfahren-Strahlschmelzen Metallischer Bauteile Charakterisierung von Pulverwerkstoffen; Verein Deutscher Ingenieure: Düsseldorf, Germany, 2019.

14. Zou, R.P.; Yu, A.B. Evaluation of the packing characteristics of mono-sized non-spherical particles. Powder Technol. 1995, 71-79. [CrossRef]

15. Brika, S.E.; Letenneur, M.; Dion, C.A.; Brailovski, V. Influence of particle morphology and size distribution on the powder flowability and laser powder bed fusion manufacturability of Ti-6Al-4V alloy. Addit. Manuf. 2020, 31, 100929. [CrossRef]

16. Cherry, J.A.; Davies, H.M.; Mehmood, S.; Lavery, N.P.; Brown, S.G.R.; Sienz, J. Investigation into the effect of process parameters on microstructural and physical properties of 316L stainless steel parts by selective laser melting. Int. J. Adv. Manuf. Technol. 2015, 76, 869-879. [CrossRef]

17. Di, W.; Song, C.; Yang, Y.; Bai, Y. Investigation of crystal growth mechanism during selective laser melting and mechanical property characterization of 316L stainless steel parts. Mater. Des. 2016, 100, 291-299.

18. Yakout, M.; Elbestawi, M.A.; Veldhuis, S.C. On the characterization of stainless steel 316L parts produced by selective laser melting. Int. J. Adv. Manuf. Technol. 2018, 95, 1953-1974. [CrossRef]

19. Song, B.; Dong, S.; Deng, S.; Liao, H.; Coddet, C. Microstructure and tensile properties of iron parts fabricated by selective laser melting. Opt. Laser Technol. 2014, 56, 451-460. [CrossRef]

20. Yusuf, S.; Chen, Y.; Boardman, R.; Yang, S.; Gao, N. Investigation on Porosity and Microhardness of 316L Stainless Steel Fabricated by Selective Laser Melting. Metals 2017, 7, 64. [CrossRef]

21. Li, R.; Liu, J.; Shi, Y.; Du, M.; Xie, Z. 316L Stainless Steel with Gradient Porosity Fabricated by Selective Laser Melting. J. Mater. Eng. Perform. 2010, 19, 666-671. [CrossRef]

22. Sun, Z.; Tan, X.; Tor, S.B.; Yeong, W.Y. Selective laser melting of stainless steel 316L with low porosity and high build rates. Mater. Des. 2016, 104, 197-204. [CrossRef]

23. Li, R.; Shi, Y.; Wang, Z.; Wang, L.; Liu, J.; Jiang, W. Densification behavior of gas and water atomized 316L stainless steel powder during selective laser melting. Appl. Surf. Sci. 2010, 256, 4350-4356. [CrossRef]

24. Casati, R.; Lemke, J.; Vedani, M. Microstructure and Fracture Behavior of 316L Austenitic Stainless Steel Produced by Selective Laser Melting. J. Mater. Sci. Technol. 2016, 32, 738-744. [CrossRef]

25. Kruth, J.-P.; Badrossamay, M.; Yasa, E.; Deckers, J.; Thijs, L.; van Humbeeck, J. Part and material properties in selective laser melting of metals. In Proceedings of the 16th International Symposium on Electromachining, ISEM 2010, Shanghai, China, 19-23 April 2010.

26. Chen, W.; Yin, G.; Feng, Z.; Liao, X. Effect of Powder Feedstock on Microstructure and Mechanical Properties of the 316L Stainless Steel Fabricated by Selective Laser Melting. Metals 2018, 8, 729. [CrossRef]

27. Spierings, A.B.; Levy, G. Comparison of density of stainless steel 316L parts produced with selective laser melting using different powder grades. In Proceedings of the Solid Freeform Fabrication Proceedings, Austin, TX, USA, 3-5 August 2009.

28. Cooke, A.; Slotwinski, J. Properties of Metal Powders for Additive Manufacturing: A Review of the State of the Art of Metal Powder Property Testing; National Institute of Standards and Technology IR: Washington, DC, USA, 2012; pp. 1-18. [CrossRef]

29. Deutsches Institut für Normung e. V. Nichtrostende Stähle-Teil 1: Verzeichnis Der Nichtrostenden Stähle; Beuth Verlag GmbH: Berlin, Germany, 2014.

30. Deutsches Institut für Normung e. V. Metallpulver_Ermittlung der Fülldichte; Beuth Verlag GmbH: Berlin, Germany, 2018.

31. Deutsches Institut für Normung e. V. Metallpulver—Bestimmung der Durchflussrate mit Hilfe Eines Kalibrierten Trichters (Hall flowmeter) (ISO 4490:2018); Beuth Verlag GmbH: Berlin, Germany, 2018. 
32. Meiners, W. Direktes Selektives Laser Sintern Einkomponentiger Metallischer Werkstoffe; Aachen, Technology Hochsch. Diss.: Aachen, Germany, 1999.

33. Hitzler, L.; Hirsch, J.; Heine, B.; Merkel, M.; Hall, W.; Öchsner, A. On the Anisotropic Mechanical Properties of Selective Laser-Melted Stainless Steel. Materials 2017, 10, 1136. [CrossRef] [PubMed]

34. Schulze, D. Pulver und Schüttgüter. Fließeigenschaften und Handhabung, 2nd ed.; Springer: Berlin/Heidelberg, Germany, 2009.

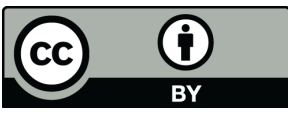

(C) 2020 by the authors. Licensee MDPI, Basel, Switzerland. This article is an open access article distributed under the terms and conditions of the Creative Commons Attribution (CC BY) license (http://creativecommons.org/licenses/by/4.0/). 